Review

\title{
Kinetic Models for Anaerobic Fermentation Processes-A Review
}

\author{
Emmanuel Amagu Echiegu \\ Department of Agricultural and Bioresources Engineering, University of Nigeria, Nsukka, Nigeria
}

\author{
Article history \\ Received: 02-11-2014 \\ Revised: 28-02-2015 \\ Accepted: 19-03-21015 \\ E-mail: emmanuel.echiegu@unn.edu.ng
}

\section{Introduction}

Anaerobic fermentation is a process which utilizes a group of anaerobic microorganisms for the stabilization of waste and biogas generation. The waste stabilization efficiency of the process is measured by the Chemical Oxygen Demand (COD) or the Volatile Solids (VS) reduction. Among other operating parameters such as temperature, loading rate, $\mathrm{pH}$, etc this efficiency depends on the rate at which the microorganism is generated in the system which in turn depends on the rate of substrate utilization. A number of models have been developed to predict the performance of anaerobic reactors in terms of biomass generation rate, substrate utilization, organic solids reduction and hence waste stabilization as well as biogas production. Reviewed in the study are some of these basic models.

\section{Microbial Growth}

When a small number of viable bacterial cells are placed in a closed system containing excess nutrient supply and maintained in a suitable environmental condition, unrestricted growth of bacteria takes place. The generation time can vary from up to 80 days to less than 20 min depending on the specie. The increase in cell mass and bacterial population will continue until the nutrient is exhausted.

The growth of pure bacterial culture in a batch system measured by increased in bacterial population usually follows a pattern similar to the growth curve shown in Fig. 1. The curve is divided into six well defined phases as follows:
- Lag phase-represents the time required by the bacteria to acclimatize to the new environment. This phase is characterized by long generation time, zero growth rate and maximum rate of metabolic activity

- Acceleration phase-represents the end of adaptation period and the beginning of cell generation. It is characterized by decreasing generation time and increasing growth rate

- Exponential or logarithmic phase-characterized by minimal but constant generation time and maximum rate of substrate utilization (and biogas yield in the case of anaerobic digestion)

- Declining growth phase-occurs as a result of gradual decrease in substrate concentration as well as increased accumulation of toxic metabolites. The phase in characterized by increased generation time and decreased growth rate

- Stationary phase-in which the microbial population remains constant generally as a result of depletion of substrate, maximum physical crowding, higher concentration of toxic metabolites and/or balance between growth and death rate of biological cells

- Endogenous decay-in which death rate exceeds growth rate. The phase is characterized by endogenous metabolism and cell lysis and is usually the inverse of exponential growth phase

As noted by (Benefield and Randall, 1980), the growth cycle just described is not a basic property of the bacterial cells but rather a result of their interaction with a closed environment. In an open system such as continuous flow process, it is possible to maintain the cells in the exponential growth phase over a long period of time. 


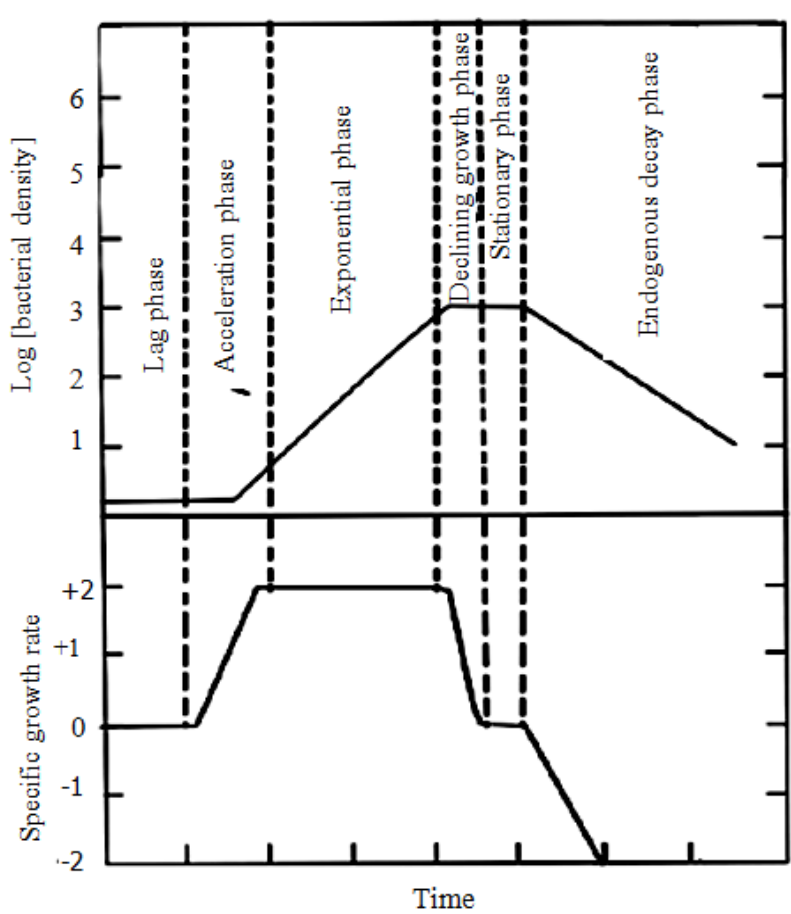

Fig. 1. Characteristic growth curve of microbial culture (Benefield and Randall, 1980)

The objective of anaerobic digestion and other waste stabilization processes from the kinetic point of view is to maintain the system in this phase.

\section{Basic Kinetic Models for Microbial Growth and Substrate Utilization}

The growth rate of a batch culture under the exponential phase is generally believed to follow the first order kinetic model i.e., the growth rate is proportional to the microbial mass in the system. Mathematically:

$\frac{d X}{d t}=\mu X$

Where:

$\frac{d X}{d t}=$ The bacterial growth rate $(\mathrm{mg} / \mathrm{L} . \mathrm{s})$

$X=$ The bacterial cell concentration $(\mathrm{mg} / \mathrm{L})$ and

$\mu=$ The proportionally constant known as the Specific Growth Rate $\left(\mathrm{s}^{-1}\right)$

As long as there is no change in biomass composition and the food supply is not limited, the relationship holds. On the other hand, if any of the essential nutrients is present in limited quantity, it will be depleted first and growth will cease-the maximum growth rate attained being proportional to the initial concentration of the "growth limiting nutrient" in the substrate. Growth, however, does not increase indefinitely with the concentration of the growth limiting nutrient originally present in the substrate but reaches a maximum after which further increase in nutrient concentration does not result in any significant increase in growth rate. The relationship is illustrated in Fig. 2 (Grady and Lim, 1980).

A variety of empirical models describing this phenomenon has been presented. However, the models presented by (Monod, 1950; Contois, 1959) seem to enjoy the widest acceptance. These are respectively given as Equations 2 and 3:

$$
\begin{gathered}
\mu=\frac{\mu_{m} S}{K_{s}+S} \\
\mu=\frac{\mu_{m} S}{b X+S}
\end{gathered}
$$

Where:

$\mu_{m}=$ The maximum specific growth rate $\left(\mathrm{s}^{-1}\right)$

$S=$ The concentration of growth limiting substrate $(\mathrm{mg} / \mathrm{L})$

$K_{s}=$ The half velocity constant i.e., the substrate concentration at one half the maximum growth rate (Fig. 2) $(\mathrm{mg} / \mathrm{L}), b$ kinetic parameter and $X$ the biomass concentration in the system $(\mathrm{mg} / \mathrm{L})$. Combining Equations 1 and 2 yields:

$\frac{d X}{d t}=\frac{\mu_{m} X S}{K_{s}+S}$

Similarly, the rate of substrate utilization can be described as:

$-\frac{d S}{d t}=\frac{k X S}{K_{s}+S}$

where, $-\frac{d S}{d t}$ is the rate of substrate consumption (g/L.s), $k$ maximum rate of substrate utilization (mg/L.s). Equation 5 shows that an increase in biomass concentration results in increased rate of substrate utilization. Defining Growth Yield $(Y)$ as the ratio of biomass yield rate to substrate consumption rate, then:

$Y=\frac{\left(\frac{d X}{d t}\right)}{\left(\frac{d S}{d t}\right)}$

Or:

$\frac{d X}{d t}=Y \frac{d S}{d t}$ 


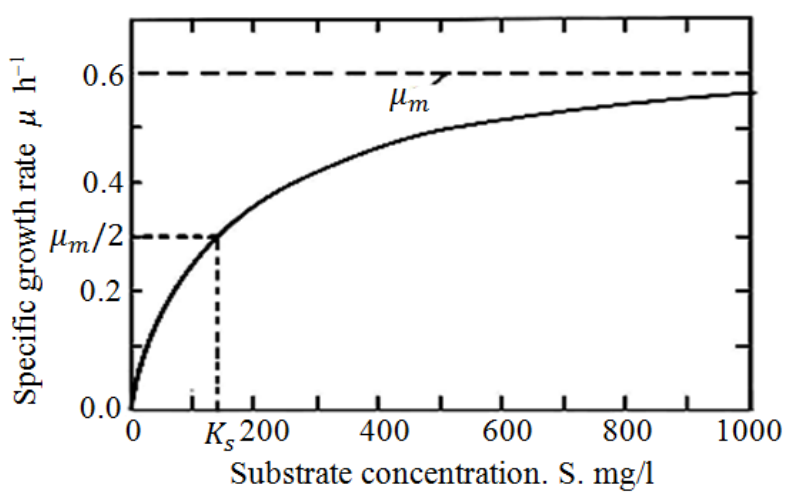

Fig. 2. Relationship between specific growth rate and concentration of growth limiting nutrient (Grady and Lim, 1980)

Expressing $\frac{d S}{d t}$ in terms of $Y$ in Equation 6 and combining with (4) yields:

$\frac{d S}{d t}=\frac{-\mu_{m} X S}{Y\left(K_{s}+S\right)}$

which combined with Equation 5 yields:

$k=\frac{-\mu_{m}}{Y}$

\section{Effects of Microbial Death and Endogenous Decay}

A viable cell is one which will divide and form a colony on a favourable media. Under certain circumstances, this ability to subdivide is lost by cells. Such morbid cells can therefore not operate in the exponential phase and are committed to death. Some cells also fall prey to predators such as rotifers and protozoa. To account for the fact that a portion of the bacterial population present in a given biological system do not actually contribute to the activities therein, the effect of death, loss of viability and energy required for maintenance are often lumped together as Endogenous Decay with the assumption that the decrease in cell mass concentration is proportional to the biomass concentration in the system. Thus:

$$
\frac{d X_{d}}{d t}=-k_{d} X
$$

Where:

$\begin{aligned} k_{d}= & \text { The death rate (endogenous decay) coefficient } \\ & \left(\mathrm{s}^{-1}\right) \text { and }\end{aligned}$ $\frac{d X_{d}}{d t}=$ The rate of decrease in cell mass concentration due to endogenous decay (mg/L.s). Thus the net bacterial growth rate is given by:

$\frac{d X^{\prime}}{d t}=\left(\mu-k_{d}\right) X=\left(\frac{\mu_{m} S}{K_{s}+S}-k_{d}\right) X=\mu^{\prime} X$

Where:

$X^{\prime}=$ Net cell mass concentration in the system $(\mathrm{mg} / \mathrm{L})$ and $\mu^{\prime}=$ The net specific growth rate $\left(\frac{\mu_{m} S}{K_{s}+S}-k_{d}\right)\left(\mathrm{s}^{-1}\right)$. Combining Equations 7 and 11 yields:

$\frac{d X^{\prime}}{d t}=Y\left(\frac{d S}{d t}\right)-k_{d} X$

And substituting for $\mu_{m}=Y_{k}$ from Equation (9) in (11) gives:

$\frac{d X^{\prime}}{d t}=\left(\frac{Y k S}{K_{s}+S}-k_{d}\right) X$

The Observed Yield (net yield) may therefore be defined as:

$Y^{\prime}=\frac{\left(\frac{d X^{\prime}}{d t}\right)}{\left(\frac{d S}{d t}\right)}$

\section{Effects of Temperature}

Temperature affects the rate of biochemical reactions. Although many relationships have been proposed to account for the effects of temperature, the most widely accepted is the van't Hoff's relationship given by:

$r_{T}=r_{o}[\theta]^{\left(T-T_{o}\right)}$

Where:

$r_{T}=$ The reaction rate $(\mu$ or $k)$ at any given temperature $T\left({ }^{\circ} \mathrm{C}\right)$

$r_{\circ}=$ The reaction rate at a reference temperature $T_{o}$ and

$\theta=$ The temperature activity coefficient

For most biochemical operations, the reference temperature is taken as $20^{\circ} \mathrm{C}$ (Metcalf and Eddy, 1978; 2003) and $\theta$ is determined as the antilog of the slope of the plot of $\log \left[\frac{r_{T}}{r_{o}}\right] v s\left(T-T_{o}\right)$.

The applications of the growth rate and substrate utilization models to various reactor systems are now discussed. 


\section{Batch Reactors}

\section{Cell Mass Balance}

$$
\left[\begin{array}{c}
\text { Net rate of } \\
\text { cell mass } \\
\text { accumulation } \\
\text { in the system }
\end{array}\right]=\left[\begin{array}{l}
\text { Rate of } \\
\text { biomass } \\
\text { formation }
\end{array}\right]
$$

That is:

$$
\left[\frac{d X^{\prime}}{d t}\right]_{n} V=\frac{d X^{\prime}}{d t} V
$$

where, $\left[\frac{d X^{\prime}}{d t}\right]_{n}$ is the net rate of biomass accumulation $(\mathrm{mg} / \mathrm{L} . \mathrm{s})\left(=\mu^{\prime} X\right)$. Integrating between time, $t=0$ and $t$ :

$$
\int_{X_{o}}^{x} \frac{d X^{\prime}}{d t}=\mu^{\prime} \int_{0}^{t} d t
$$

Or:

$$
X=X_{o} e^{\mu t}
$$

where, $\mathrm{X}_{\mathrm{o}}$ is the initial biomass concentration at time $t$ $=0$ i.e., biomass concentration in the seed material $(\mathrm{mg} / \mathrm{L})$ and $X$ is the biomass concentration in the reactor at time $t$ from start.

\section{Substrate Mass Balance}

By methods similar to cell mass balance, the substrate concentration at time, $t$ can be determined as:

$$
S=S_{o} e^{-k t}
$$

Where:

$S_{o}=$ The initial substrate concentration $(\mathrm{mg} / \mathrm{L})$

$S=$ The substrate concentration in the reactor at time $t$ from start $(\mathrm{mg} / \mathrm{L})$

$k=$ The substrate utilization rate $\left(\mathrm{s}^{-1}\right)$. Therefore the time required to achieve the desired effluent concentration is:

$$
t=\frac{1}{k} \ln \ln \left[\frac{S_{o}}{S}\right]
$$

\section{Continued Stirred Tank Reactors (CSTR) with Simple Biomass and Substrate System}

The system is shown schematically in Fig. 3 where $Q$ is the liquid flow rate $(\mathrm{L} / \mathrm{s})$ and $V$ is the volume of the reactor $(\mathrm{L})$.

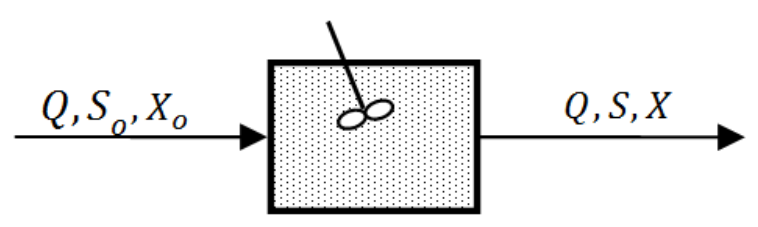

Fig. 3. Flow scheme for a CSTR

\section{Cell Mass Balance}

$$
\left[\begin{array}{c}
\text { Net rate of } \\
\text { cell mass } \\
\text { accumulation } \\
\text { in the system }
\end{array}\right]=\left[\begin{array}{c}
\text { Inflow } \\
\text { rate } \\
\text { of } \\
\text { biomas }
\end{array}\right]-\left[\begin{array}{l}
\text { Out flow } \\
\text { rate }
\end{array}\right]+\left[\begin{array}{l}
\text { Rate of } \\
\text { biomass } \\
\text { generation }
\end{array}\right]
$$

That is:

$\left[\frac{d X^{\prime}}{d t}\right]_{n} V=Q X_{o}-Q X+\frac{d X^{\prime}}{d t} V$

where, $X_{o}$ and $X$ are influent and effluent cell mass concentration, respectively $(\mathrm{mg} / \mathrm{L})$ and $\left[\frac{d X^{\prime}}{d t}\right]_{n}$ is the net rate of change of biomass concentration within the system (mg/L.s). Assuming that the influent biomass concentration is negligible and that steady state condition prevail, i.e., $\left[\frac{d X^{\prime}}{d t}\right]_{n}=0$ and combining Equation 11 and 20 and simplifying yields:

$\frac{1}{\theta_{h}}=\frac{\mu_{m}^{\prime} S}{K_{s}+S}-k_{d}=\mu^{\prime}$

Or:

$\frac{1}{\theta_{h}}=\frac{Y k S}{K_{s}+S}-k_{d}$

where, $\theta_{h}$ is the hydraulic retention time $=\mathrm{V} / \mathrm{Q}$ (days). Also the biological Solid Retention Time (SRT) is defined as:

$\theta_{c}=\frac{X_{T}}{\left[\frac{d X}{d t}\right]_{w}}$

Where:

$\theta_{c} \quad=$ The solid retention time $(\mathrm{d})$

$X_{T} \quad=$ The total biomass in the system $=V X(\mathrm{~g})$ and

$\left[\frac{d X}{d t}\right]_{w}=$ The rate biomass wastage from the system $=$ $Q X(\mathrm{~g} / \mathrm{L})$. Thus: 
$\theta_{c}=\frac{V X}{Q X}=\theta_{h}=\frac{1}{\mu^{\prime}}$

Thus in a CSTR without cell mass recycle:

$\theta_{h}=\theta_{c}$

\section{Substrate Mass Balance}

$\left[\begin{array}{c}\text { Net rate of } \\ \text { substrate } \\ \text { accumulation } \\ \text { in the system }\end{array}\right]=\left[\begin{array}{c}\text { Inflow } \\ \text { rate } \\ \text { of } \\ \text { substrate }\end{array}\right]-\left[\begin{array}{l}\text { Out flow } \\ \text { rate }\end{array}\right]+\left[\begin{array}{l}\text { Rate of } \\ \text { substrate } \\ \text { consumption }\end{array}\right]$

Or:

$\left[\frac{d S}{d t}\right]_{n} V=Q S_{o}-Q S+\frac{d S}{d t} V$

where, $S_{o}$ and $S$ are influent and effluent substrate concentration, respectively $(\mathrm{g} / \mathrm{L})$ and $\left[\frac{d S}{d t}\right]_{n}$ is the net rate of change of substrate accumulation within the system (g/L.s). At steady state $\left[\frac{d S}{d t}\right]_{n}=0$. Combining Equation 5 and 26, assuming steady state and simplifying yields:

$\frac{S_{o}-S}{\theta_{h}}=\frac{k X S}{K_{s}+S}=\frac{d S}{d t}$

\section{Effluent Biomass and Substrate Concentration}

From Equation 21:

$\frac{S}{K_{s}+S}=\frac{1+k_{d} \theta_{h}}{\mu_{m} \theta_{h}}$

Substituting Equation 28 in 27 and solving for $\mathrm{X}$ while nothing that $\mu_{m}=Y_{k}$ yields:

$X=\frac{Y\left(S_{o}-S\right)}{1+k_{d} \theta_{h}}$

Substituting for $\theta_{c}=\theta_{h}$ in Equation 22 and solving for $S$ yields:

$S=\frac{K_{s}\left[1+k_{d} \theta_{c}\right]}{\theta_{c}\left(Y k-k_{d}\right)-1}$

Various parameters have been used to approximate biological solids concentration $(X)$. These include: The dry weight of suspended matter present in the system i.e., total suspended solids (Thimann, 1955; Echiegu, 1992; Echiegu and Ghaly, 1993; Ghaly and Echiegu, 1993; Echiegu and Ghaly, 2014), the quantity of cellular constituents such as carbon, nitrogen and phosphorus (Agardy et al., 1963; Lawrence and McCarty, 1969), DNA content (Agardy et al., 1963), ATP content (Holm-Hansen and Both, 1966) and number of living cells per unit volume. However the most widely accepted parameter for the approximation of active biomass concentration is Volatile Suspended Solids (VSS) (Stewart, 1958; Andrew et al., 1964; Lawrence and McCarty, 1969; Toerien et al., 1967; Metcalf and Eddy, $1978 ; 2003)$ as the use of most of the other parameters has some inherent problems (Preterious, 1969).

Substrate concentration is usually measured as total dissolved solids, BOD or COD. Where any particular nutrient is considered as rate-limiting and is being investigated, its concentration can also be used as the limiting substrate concentration $S$. Generally, however, for anaerobic digestion of animal waste, COD is used as an estimate of the substrate content of the feedstock.

\section{Other Design Parameters}

Although the effluent solids and substrate concentrations can be determined from Equation 29 and 30 respectively, the kinetic constants are often difficult to determine. This fact has led to the development of other more useful parameters.

\section{Specific Substrate Utilization (U)}

This is defined as the amount of substrate utilized by a given quantity of microbial cells per given time, i.e.,:

$U=\frac{\left(\frac{d S}{d t}\right)}{X}=\frac{S_{o}-S}{X \theta_{c}}$

Dividing Equation 12 by $X$ and using the definition of $\theta_{c}$ and $U$ from Equation 23 and 31, respectively yields:

$\frac{1}{\theta_{c}}=Y U-k_{d}$

Substituting for $\frac{d S}{d t}=U X$ from (31) and $\frac{d X^{\prime}}{d t}$ from (12) in (14) and rearranging yields:

$Y^{\prime}=\frac{Y U-k_{d}}{U}$

and substituting for $U$ from Equation (32) in (33) yields:

$Y^{\prime}=\frac{Y}{1+\theta_{c} k_{d}}$ 
Equating 21 and 32 and solving for $S$ while nothing that $\mu_{m}=Y_{k}$ gives:

$$
S=\frac{U K_{s}}{k-U}
$$

\section{Food to Micro-Organism (F/M) Ratio}

This is defined as:

$$
F / M=\frac{S_{o}}{\theta_{h} X}
$$

\section{Efficiency of the Process ( $\eta$ )}

This is defined as:

$$
\eta=\frac{100\left(S_{o}-S\right)}{S_{o}}
$$

Combining (36) and (37) with (31) gives:

$$
U=\frac{\eta(F / M)}{100}
$$

Efficiency is a function of the microbial cell population in and the SRT of the system. The relationship between efficiency $(\eta)$ and $\operatorname{SRT}\left(\theta_{c}\right)$ is shown in Fig. 4. The figure indicates that for any given substrate and operating conditions, there exist an optimum retention time beyond which little added benefit in treatment efficiency is obtained. At higher SRT, the effect of temperature becomes negligible (Parkin and Owen, 1986). The effect of SRT on temperature and treatment efficiency is shown in Fig. 5.

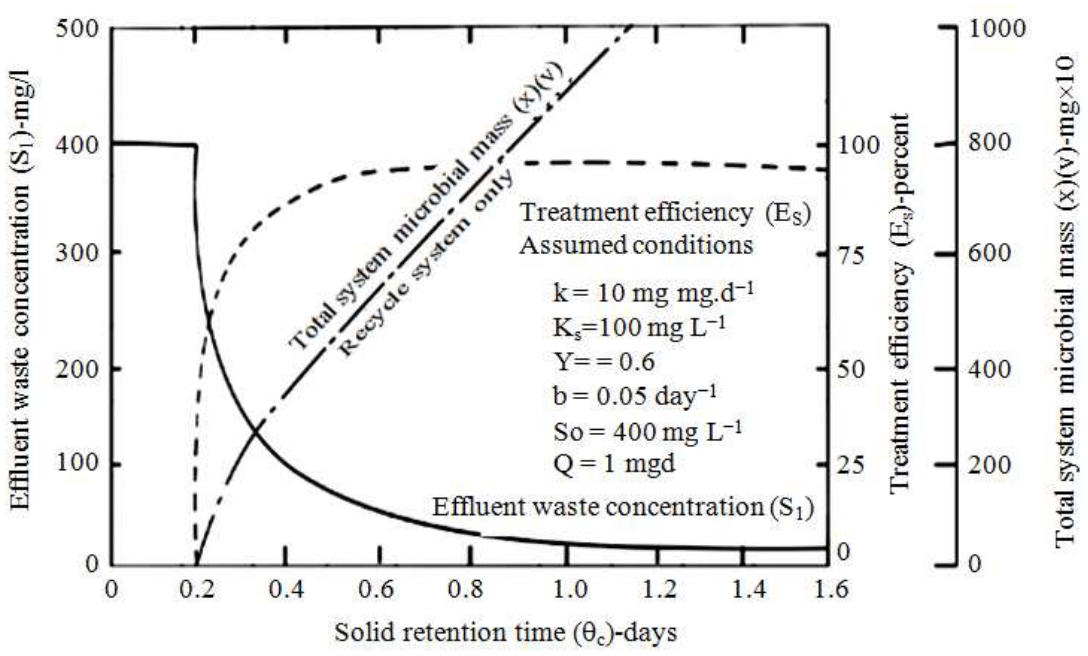

Fig. 4. Steady-state relationship between specific treatment efficiency, effluent substrate concentration, total biomass concentration and SRT (Lawrence and McCarty, 1969)

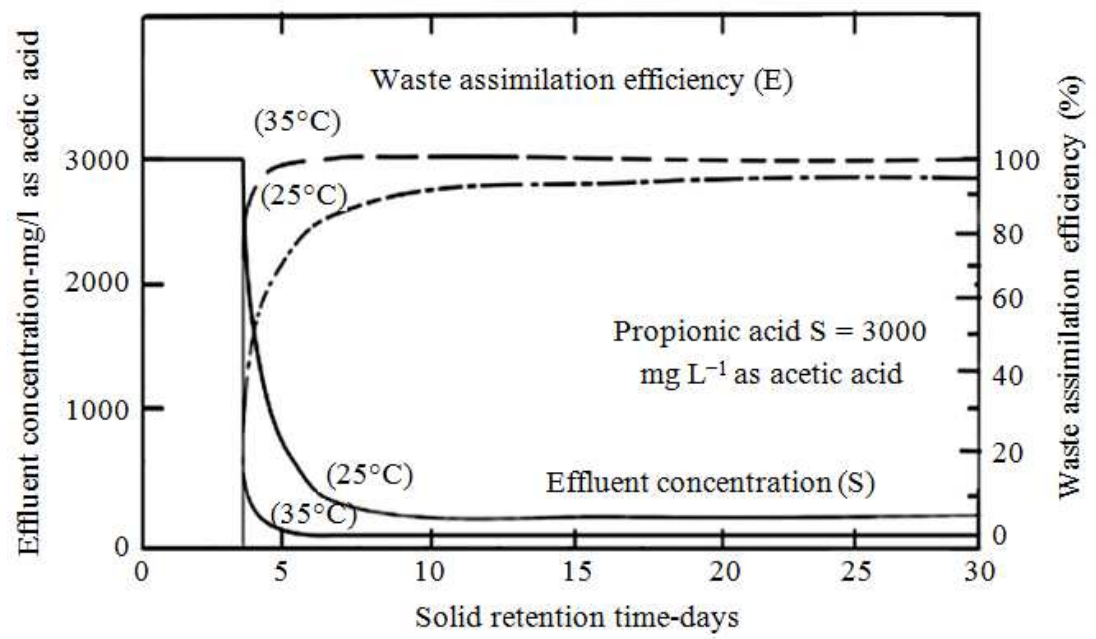

Fig. 5. Effect of SRT on temperature and steady-state treatment efficiency (Lawrence and McCarty, 1969) 


\section{Determination of Kinetic Parameters}

Dividing Equation 27 by $X$, taking the inverse and linearizing while noting that for a CSTR $\theta_{c} \cong \theta_{h}$ yields:

$$
\frac{X \theta_{h}}{S_{o}-S}=\frac{1}{U}=\left(\frac{K_{s}}{k}\right)\left(\frac{1}{S}\right)+\frac{1}{k}
$$

By conducting a laboratory experiment on a waste sample of known substrate (COD) concentration $\left(S_{o}\right)$, determining the effluent substrate $(S)$ and biomass $(X)$ concentrations for various retention times $\left(\theta_{h}\right)$ and carrying out a plot of $(1 / U)$ Vs $(1 / S)$, the maximum substrate utilization rate $(k)$ is determined as the reciprocal of the intercept of the plot while the half velocity constant $\left(K_{s}\right)$ is determined as the product of $k$ and the slope of the plot (Fig. 6).

Also by plotting $\left(1 / \theta_{h}\right)$ Vs $U$ (Equation 32$)$, the growth yield $(Y)$ is determined as the slope while the endogenous decay coefficient $\left(k_{d}\right)$ is determined as the intercept of the plot (Fig. 6). Values of kinetic constants for simple substrates as compiled by Mossey (1983) are shown in Table 1.

\section{Concept of Microbial Washout and Safety Factor}

At a detention time equal to or less than the minimum detention time, the influent and effluent substrate concentrations are equal. Thus from Equation 22:

$$
\theta_{c}^{\min }=\left[\frac{Y k S_{o}}{K_{s}+S_{o}}-k_{d}\right]^{-1}
$$

and where $K_{s}<<\mathrm{S}_{\mathrm{o}}$ :

$$
\theta_{c}^{\lim }=\left[Y k-k_{d}\right]^{-1}
$$

Where:

$\theta_{c}^{\min }=$ Minimum solid retention time (days)

$\theta_{c}^{\lim }=$ The limiting SRT (i.e., bacterial generation time)

If a particular treatment efficiency $(\eta)$ is desired, the appropriate detention time to use is given by:

$\theta_{c}^{d}=\left[\frac{Y k(1-\eta) S_{o}}{K_{s}+(1-E) S_{o}}-k_{d}\right]^{-1}$

Where:

$\theta_{c}^{d}=$ The design detention time and

$\eta=$ The desired treatment efficiency (decimal)

The ratio of deign to minimum detention time equals the Safety Factor (SF), i.e.,:

$S F=\frac{\theta_{c}^{d}}{\theta_{c}^{\min }}$

and ranges from 2.5 to 10 (Lawrence and McCarty, 1970; Lawrence, 1971).

Table 1. Values of kinetic constants ${ }^{\mathrm{a}}$

\begin{tabular}{llllll}
\hline Substrate & $\begin{array}{l}\text { Temp } \\
\left({ }^{\circ} \mathrm{C}\right)\end{array}$ & $\begin{array}{l}Y \\
(\mathrm{mg} / \mathrm{mg} . \mathrm{d})\end{array}$ & \multicolumn{1}{l}{$\begin{array}{l}K_{s} \\
(\mathrm{mg} / \mathrm{mg} . \mathrm{d})\end{array}$} & $\begin{array}{l}K_{d} \\
(\mathrm{mg} / \mathrm{L})\end{array}$ & \multicolumn{1}{l}{$\left.\mathrm{d}^{-1}\right)$} \\
\hline Acetate & 35 & 0.040 & 8.10 & 154 & 0.019 \\
& 30 & 0.054 & 4.80 & 333 & 0.037 \\
& 25 & 0.050 & 4.70 & 869 & 0.011 \\
Propionate & 35 & 0.042 & 9.60 & 32 & 0.010 \\
& 25 & 0.051 & 9.80 & 613 & 0.040 \\
Butyrate & 35 & 0.047 & 15.60 & 5 & 0.027 \\
Long chain & 35 & 0.120 & 6.67 & 680 & 0.015 \\
fatty acid & 25 & 0.120 & 4.65 & 1270 & 0.015 \\
& 20 & 0.120 & 3.85 & 1580 & 0.015 \\
Glucose & 37 & 0.173 & 30.00 & 23 & 0.800 \\
\hline a Mossey $(1983)$ & & & &
\end{tabular}
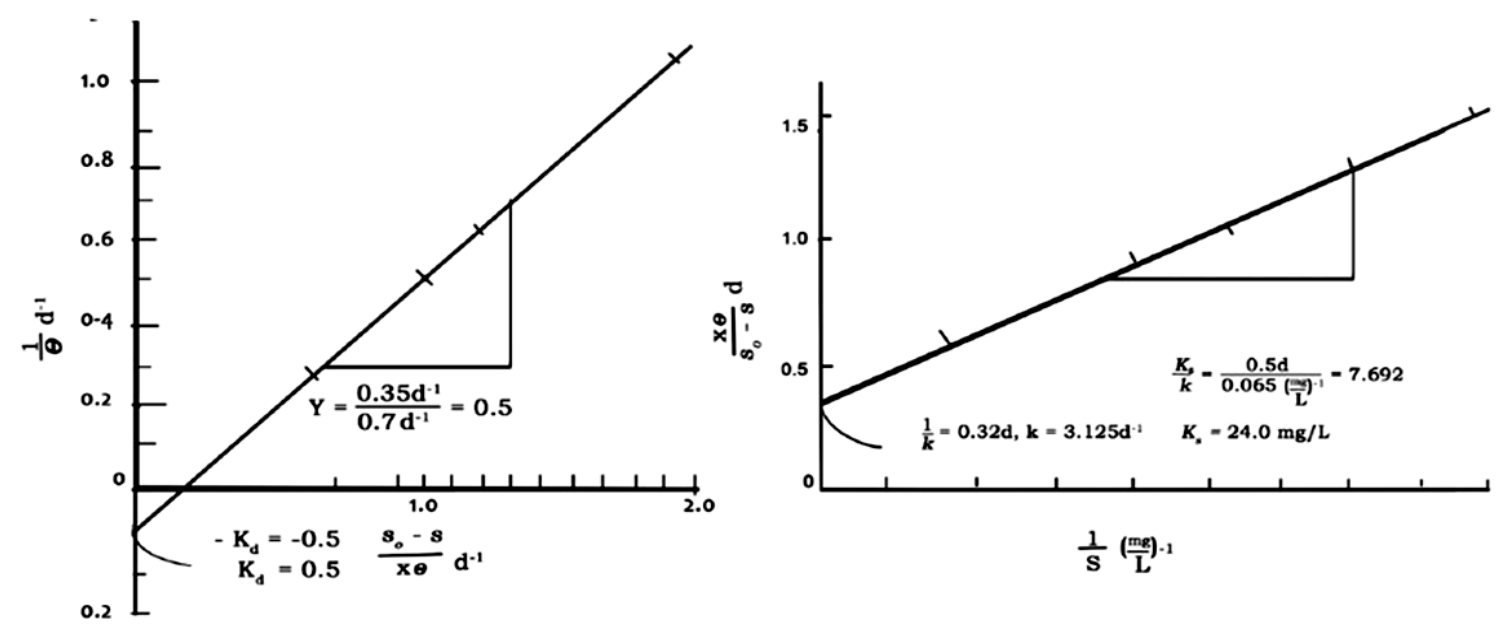

Fig. 6. Determination of kinetic parameters (Metcalf and Eddy, 1978) 


\section{Anaerobic Contact Process}

The anaerobic contact reactor is shown schematically in Fig. 7. Referring to the figure, Let:

$Q=$ Influent flow rate of substrate into the reactor $\left(\mathrm{m}^{3} / \mathrm{d}\right)$

$S_{o}=$ Reactor influent substrate concentration $\left(\mathrm{kg} / \mathrm{m}^{3}\right)$

$X_{o}=$ Reactor influent biomass concentration $\left(\mathrm{kg} / \mathrm{m}^{3}\right)$

$S_{l}=$ Effluent (or biomass separator influent) substrate concentration $\left(\mathrm{kg} / \mathrm{m}^{3}\right)$

$X_{I}=$ Effluent (or biomass separator influent) biomass concentration $\left(\mathrm{kg} / \mathrm{m}^{3}\right)$

$q_{r}=$ Flow rate of recycle liquid $\left(\mathrm{m}^{3} / \mathrm{d}\right)$

$X_{r}=$ Biomass concentration of recycle solids $\left(\mathrm{kg} / \mathrm{m}^{3}\right)$

$q_{w}=$ Wastage rate from the recycle line $\left(\mathrm{m}^{3} / \mathrm{d}\right)$ and

$X=$ Final effluent biomass concentration $\left(\mathrm{kg} / \mathrm{m}^{3}\right)$

Therefore the effluent flow rate from the reactor equals $\left(Q+q_{r}\right)$ which in turn equals the influent flow rate into the separator. The effluent flow rate from the separator equals $\left(Q-q_{w}\right)$ assuming there is no substrate utilization in the separator, the influent substrate concentration into the separator $\left(S_{i}\right)$ equals the effluent concentration from the separator $(S)$ which in turn equals the substrate concentration in the recycle line and from the definition of SRT:

$\theta_{c}=\frac{\text { Total cell mass content of the reactor }}{\text { rate of cell mass wastage from the reactor }}$

That is:

$\theta_{c}=\frac{V X_{1}}{\left(Q-q_{w}\right) X+q_{w} X_{r}}$

\section{Cell Mass Balance}

Accumulation=Inflow-Outflow + Net growth.

That is:

$$
V\left[\frac{d X^{\prime}}{d t}\right]_{n}=Q X_{o}-\left[q_{w} X_{r}+\left(Q-q_{w}\right) X\right]+V \frac{d X^{\prime}}{d t}
$$

At steady state and assuming no cell concentration in the influent:

$$
V \frac{d X^{\prime}}{d t}=q_{w} X_{r}+\left(Q-q_{w}\right) X
$$

Substituting for $\frac{d X^{\prime}}{d t}$ from (13) and simplifying yields:

$$
\frac{Y K S_{1}}{K_{s}+S_{1}}-k_{d}=\frac{q_{w} X_{r}+\left(Q-q_{w}\right) X}{V X_{1}}=\frac{1}{\theta_{c}}
$$

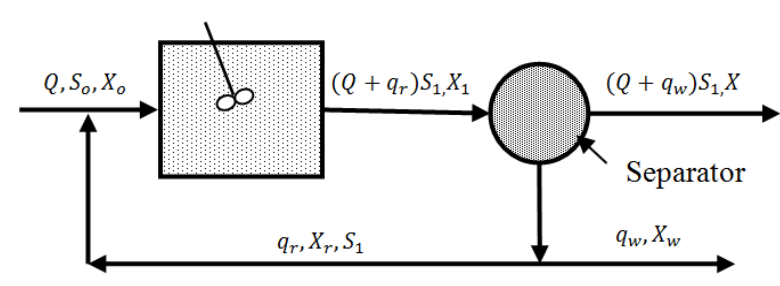

Fig. 7. Flow scheme of anaerobic contact process

which is the same as for CSTR.

Also carrying out the mass balance about the reactor alone at steady state yields:

$$
Q X_{o}+q_{r} X_{r}+V \frac{d X^{\prime}}{d t}-\left(Q-q_{r}\right) X_{1}=0
$$

Assuming that there are no biological cells in the influent and substituting values for $\frac{d X^{\prime}}{d t}$ and simplifying yields:

$\frac{1}{\theta_{c}}=\frac{1}{\theta_{h}}\left[1+r-r\left(\frac{X_{r}}{X_{1}}\right)\right]$

where, $\theta_{h}$ is $V / T$ equals to the HRT and $r$ equals $q_{r} / Q$ equals to the recycle ratio. Equation 49 shows that the SRT is a function of the ratio $\left(\frac{X_{r}}{X_{1}}\right)$ which in turn is a function of the settling characteristics of the biomass and the efficiency of the biomass separation unit. At a separation efficiency of approximately $100 \%$, the maximum solid concentration in the recycle line is given by:

$$
\left(X_{r}\right)^{\max }=\frac{10^{6}}{S V I}
$$

where, $S V I$ is sludge volume index. Note also that is a function of the recycle ratio which implies that SRT can be controlled by controlling wastage of biomass (i.e., varying $q_{w}$ ) from the system.

\section{Substrate Mass Balance}

Substrate mass balance about the reactor alone yields (in word) Accumulation=Inflow+Recycle-OutflowConsumption.

Or mathematically:

$V\left[\frac{d S_{1}}{d t}\right]_{n}=Q S_{o}+q_{r} S_{1}-\left(Q+q_{r}\right) S_{1}-V \frac{d S_{1}}{d t}$

Substituting for $\left[\frac{d S_{1}}{d t}\right]$ from (5) at steady state and simplifying yields: 


$$
\frac{K X_{1} S_{1}}{K_{s}+S_{1}}=\frac{S_{o}-S_{1}}{\theta_{h}}
$$

\section{Effluent Biomass and Substrate Concentration}

Substituting for $\frac{K S_{1}}{K_{s}+S_{1}}$ from Equation 47 in 52 and solving for $X_{l}$ yields:

$X_{1}=\frac{Y \theta_{c}\left(S_{o}-S_{1}\right)}{\theta_{h}\left(1+\theta_{c} k_{d}\right)}$

The final effluent biomass concentration is determined by solving for $\mathrm{X}$ in Equation 47, i.e.,:

$X=\frac{\left(\theta_{h}-\theta_{c} w C\right) X_{1}}{\theta_{c}(1-w)}$

where, $w=\frac{q_{w}}{Q}$ is the wastage ratio and $C=\frac{X_{r}}{X_{i}}$ and the final effluent substrate concentration is got by solving for $S_{l}$ in Equation 47, i.e.,:

$$
S_{1}=\frac{K_{s}\left(1+\theta_{c} k_{d}\right)}{\theta_{c}\left(Y k-k_{d}\right)-1}
$$

which is the same for a CSTR. The minimum and design detention time can also be determined as for a CSTR (Equations 40 and 42).

\section{Plug Flow Reactors}

Plug Flow Reactor with Simple Substrate and Microbe System

Plug flow reactor models assumes that there is no lateral dispersion. i.e., biomass and substrate concentration at any given cross-section is constant. However, there is both a biomass and substrate concentration gradient along a time and hence along the length axis of the reactor. Thus substrate concentration decreases while biomass concentration increases as the waste moves along the length of the reactor from the influent to the effluent end.

Lawrence and McCarty (1970) have pointed out that because of interdependence between substrate removal and microbial growth, it is not possible to obtain explicit analytical solution for the system. They however noted, as operated in practice, there is usually very little difference between influent and effluent biomass concentration of the reactor and suggested the use of average value for biological cell concentration $(\bar{X})$ within the reactor to simplify the analysis. (This assumption is most valid in a reactor with $\frac{\theta_{c}}{\theta_{h}}>5.0$ ).

\section{Microbial Cell Mass Balance}

Consider an elemental volume of reactor $(d V)$ of length $(d L)$ (Fig. 8) Accumulation=Inflow-Outflow + Generation. Referring to Fig. 8:

$$
\begin{aligned}
& d V \frac{d}{d t}\left[\frac{\left.\left(\bar{X}-\frac{\partial \bar{X}}{\partial L} d L\right)+\bar{X}\right]}{2}\right] \\
& =Q\left[\bar{X}-\frac{\partial \bar{X}}{\partial L} d L\right]-Q \bar{X}+d V \mu^{i}\left[\frac{\left(\bar{X}-\frac{\partial \bar{X}}{\partial L} d L\right)+\bar{X}}{2}\right] a
\end{aligned}
$$

Assuming steady state, neglecting second order terms and simplifying yields:

$v \frac{d \bar{X}}{d t}=\frac{d \bar{X}}{d t}-\mu^{\prime} \bar{X}$

where, $v$ is the velocity. The elemental volume under consideration is analogous to a CSTR moving along a time axis. Therefore combining Equation 12 and 21 with (57) and substituting for $\frac{d S_{1}}{d t}=\frac{S_{o}-S_{1}}{\theta_{h}}$ gives:

$\frac{Y\left(S_{o}-S_{1}\right)}{\theta_{h} X}-k_{d}=\frac{1}{\theta_{c}}$

\section{Substrate Mass Balance}

Substrate balance about the element of the reactor of volume $d V$ :

$$
\begin{aligned}
& d V \frac{d}{d t}\left[\frac{S+\left(S-\frac{\partial S}{\partial L} d L\right)}{2}\right] \\
& =Q S+Q\left[S-\frac{\partial S}{\partial L} d L\right]-K d V\left[\frac{S+\left(S-\frac{\partial S}{\partial L} d L\right)}{2}\right]
\end{aligned}
$$

where, $K$ is substrate utilization coefficient (compare with $\left.\mu^{\prime}\right)$. Substituting for $K=\frac{k \bar{X}}{K_{s}+S}$, assuming steady state, neglecting second order terms and integrating gives:

$$
K_{s} \ln \left(\frac{S_{o}}{S}\right)+\left(S_{o}-S_{1}\right)=\frac{L}{v}=k \bar{X} \theta_{h}
$$




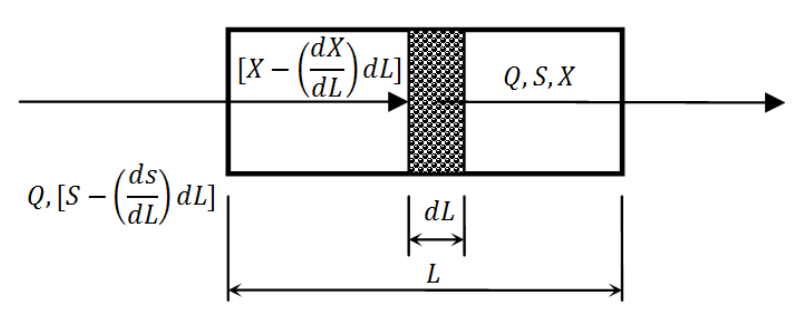

Fig. 8. Definition sketch for plug flow reactor

where, $L$ is length of reactor and $v$ flow velocity. Substituting for $\left(S_{o}-S_{l}\right)$ from Equation 58 in 60 and solving for $\bar{X}$ yields:

$$
X_{1}=\frac{Y K_{s} \theta_{c}\left(\ln \ln S_{o}-\ln \ln S\right)}{\theta_{h}\left(Y k-k_{d}\right)-1}
$$

And solving for $\bar{X} \theta_{h}$ from Equation 60 and substituting in (58) yields:

$$
\frac{1}{\theta_{c}}=\frac{Y K\left(S_{o}-S_{1}\right)}{K_{s} \ln \ln \left(\frac{S_{o}}{S}\right)+\left(S_{o}-S_{1}\right)}-k_{d}
$$

Equation 61 and 62 give effluent biomass concentration and retention time respectively. The effluent substrate concentration can be calculated from:

$$
S=S_{o} e^{-k \theta_{h}}
$$

which is obtained from direct integration of Equation 59 without substituting for the value of $K=\frac{k \bar{X}}{K_{s}+S} . K$ can be obtained experimentally in the laboratory.

\section{Plug Flow with Recycle}

The microbial mass balance around the entire system (Fig. 9) is similar to the anaerobic contact process except that the cell mass concentration in the reactor is replaced by the average biomass concentration $(\bar{X})$ as suggested by Lawrence and McCarty (1970). The resultant equation is identical to Equation 58, i.e.,:

$\frac{1}{\theta_{c}}=\frac{Y Q\left(S_{o}-S_{1}\right)}{\bar{X} V}-k_{d}$

Also carrying out substrate mass balance similar to that of plug flow without recycle results, after integrating and simplifying, to:

$$
K_{s} \ln \left(\frac{S_{o}}{S}\right)+\left(S_{i}-S_{1}\right)=k \bar{X} \theta_{h}
$$

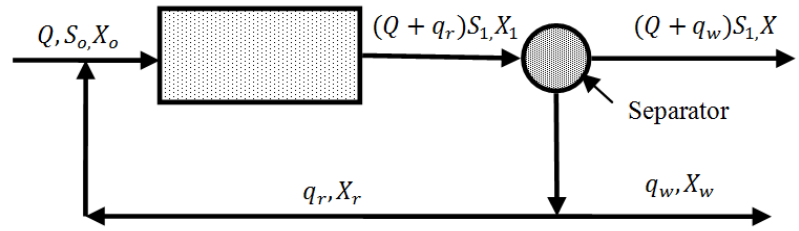

Fig. 9. Schematics of plug flow reactor with recycle

where, $S_{i}$ is the substrate concentration after mixing the influent substrate stream with the recycle stream, i.e., $S_{i}=\frac{Q S_{o}+q_{r} S_{1}}{Q+q_{r}}$ and $\theta_{h}=\frac{V}{Q+q_{r}}$.

Substituting the values of $\theta_{h}$ and $S_{i}$ in Equation 65, solving for $\bar{X} V$ and substituting in (64) gives:

$$
\begin{aligned}
& \frac{1}{\theta_{c}}=\frac{Y k\left(S_{o}-S_{1}\right)}{\left(S_{o}-S_{1}\right)+(1+r) K_{s} \ln K_{s} \ln \left[\frac{\left(r S_{1}+S_{o}\right)}{(1+r) S_{1}}\right]}-k_{d} \\
& \lim _{(r \rightarrow 0)}(1+r) \ln \left[\frac{\left(r S_{1}+S_{o}\right)}{(1+r) S_{1}}\right]=\ln \left[\frac{S_{o}}{S_{1}}\right]
\end{aligned}
$$

The approximation is usually sufficient when $r<1.0$ (Lawrence and McCarty, 1970). When this applies, Equation 66 reduces to (61).

Also substituting for $\theta_{h}=\frac{V}{Q+q_{r}}$ in (64) and (65) and for $\left(S_{o}-S_{l}\right)$ from (64) and $S_{i}$ in (65) and solving for $\bar{X}$ yields:

$$
\bar{X}=\frac{Y \theta_{c}(1+r) K_{s} \ln \left[\frac{\left(r S_{1}+S_{o}\right)}{(1+r) S_{1}}\right]}{\theta_{h}\left[\theta_{c}\left(Y k-k_{d}\right)-1\right]}
$$

\section{Plug Flow with Dispersion}

Plug flow as assumed in the analysis of CSTR and piston flow as assumed in that of plug flow are ideal situation which are seldom observed in practice. In real situations, intermediate amount of mixing generally occur. To account for such effects, Wehner and Wilhem (1956) proposed a dispersion model which approaches complete mixing when the degree of dispersion approaches infinity and converts to plug flow where there is no dispersion. The model is given in Equation 68:

$$
\frac{S_{o}}{S}=\frac{4 a e^{\left(\frac{1}{2} d\right)}}{(1+a)^{2} e^{\left(\frac{a}{2} d\right)}-(1-a)^{2} e^{\left(-\frac{a}{2} d\right)}}
$$




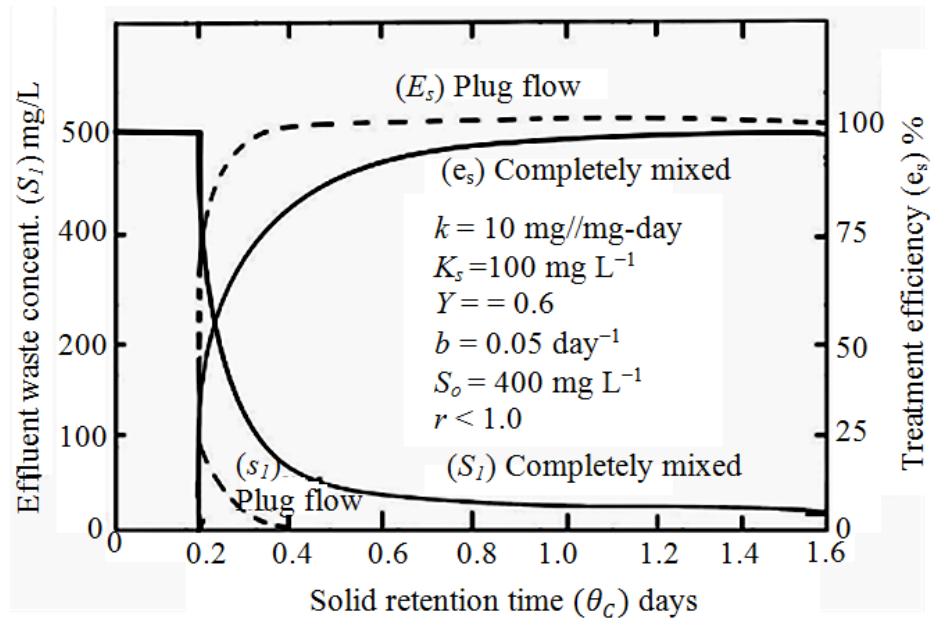

Fig. 10. Comparison of steady-state treatment efficiency and effluent substrate concentration of a plug flow reactor and a CSTR (Lawrence and McCarty, 1970)

where, $a=\left(1+4 K \theta_{h} d\right)^{2} ; \quad d=\frac{D}{v L}=\frac{D \theta_{h}}{L^{2}}=$ dispersion factor ; $D$ is the axial dispersion coefficient $\left(\mathrm{m}^{2} / \mathrm{s}\right) ; v$ is the fluid velocity $(\mathrm{m} / \mathrm{s}) ; L$ is the characteristic length of travel of path of typical particle in the reactor $(\mathrm{m})$ and $K$ is the substrate utilization coefficient $\left(\mathrm{s}^{-1}\right)$. The second term in Equation 68 is small and when neglected an approximate form of (68) is:

$$
\frac{S_{o}}{S}=\frac{4 a e^{\left[\frac{(1-a)}{2} d\right]}}{(1+a)^{2}} \text { valid for } \mathrm{d} \leq 2
$$

\section{Comparison of Plug Flow with CSTR}

Although both the plug flow and the CSTR may have the same minimum SRT for a given waste sample, true plug flow are generally more efficient than the complete mix system (Lawrence and McCarty, 1970; Metcalf and Eddy, 1978). This is illustrated in Fig. 10. However plug flow reactors have the disadvantage of being less stable under toxic or shock load conditions as such loads are concentrated at one end and not dispersed immediately as in complete mix systems. Furthermore there is a considerable evidence to indicate that in practice, true plug flow conditions do not actually occur as there is always a high degree of back-mixing in the system. The net result is that, in actual practice, the difference between the two systems are usually not significant so that the equations for CSTR may be applied to plug flow reactor with only a conservative result being yielded.

\section{Kinetics of Digestion of Complex Wastes}

The kinetic relationships so far developed refer to anaerobic digestion of simple substrates involving single microbe specie. Where complex wastes such as animal manure are involved, the rate-limiting models developed by (O'Rourke, 1968) and described in detail by (McCarty, 1964) are generally employed. O'Rourke (1968) working with primary sludge consisting essentially of fatty acids (lipids), propionic acid acetic acids found that the anaerobic digestion kinetics of complex wastes could be described by the kinetics of the breakdown of the individual components of the waste with the resultant effluent a contribution from the decomposition of the various components.

The values of the kinetic parameters $Y, k$ and $k_{d}$ (measured in terms of $\mathrm{mg} / \mathrm{L}$ COD) for the conversion of the various short chain volatile acids to methane have been found to be essentially equal at a given temperature (O'Rourke, 1968) and for different wastes, the parameters also do not vary to a significant extent for most engineering purposes (Lawrence and McCarty, 1970). The half velocity coefficient $K_{s}$ however do vary over a wide range of different substrates. It also varies with substrate concentration and together with $k$, the maximum substrate utilization rate, it varies with temperature (O'Rourke, 1968; Lawrence and McCarty, 1969; Lawrence, 1971). When it is assumed that $Y, k$ and $k_{d}$ are equal for all short chain acids of concern, the kinetic relationships already developed for simple substrates may be adapted for complex wastes by replacing $K_{s}$ by:

$K_{s}=\sum_{i=1}^{n} K_{s_{i}}$

where, $K_{s i}$ is the $K_{s}$ for component $i$ and $n$ is the number of components.

Thus the effluent substrate concentration of a CSTR without recycle $S_{o}$, for example, will be given by: 
$S_{c}=\frac{k_{L}\left(1+k_{d} \theta_{c}\right)}{\theta_{c}\left(Y k-k_{d}\right)-1}$

$\mathrm{K}_{\mathrm{s}}$ value at any given temperature can be determined with reference to a known temperature by using the formula developed for acetic acid by (Lawrence and McCarty, 1969), i.e.,:

$\log \left[\frac{K_{s_{2}}}{K_{s_{1}}}\right]=6980\left[\frac{1}{T_{2}}-\frac{1}{T_{1}}\right]$

where, $K_{s}$ is the half velocity coefficient at temperature $T_{i}$.

\section{Flocculent Bed and Fixed Film Reactors}

These include the Up-flow Anaerobic Sludge Blanket (UASB), Down-flow Stationary Fixed Film (DSFF), Suspended Particles Attached Growth Reactors (SPAG) and the No-mix energy efficient reactors as well as the Anaerobic Filter (AF). A model developed by (Bolte and Hills, 1985) can be applied for the analysis of any of these retained biomass reactors where SRT $>>$ HRT or where the relationship between the SRT and HRT can be precisely determined (empirically or otherwise).

A microbial mass and substrate balance about a CSTR without recycle can be expressed as:

$$
\begin{aligned}
& \frac{d X}{d t}=\left(\mu^{\prime}-\frac{1}{\theta_{c}}\right) X \\
& \frac{d S}{d t}=\frac{S_{o}-S}{\theta_{h}}-\frac{\mu^{\prime} X}{Y}
\end{aligned}
$$

where, $\mu^{\prime}=\left(\mu-k_{d}\right)$. Under steady state, Equation 73 and 74 reduce respectively to:

$$
\mu-k_{d}=\frac{1}{\theta_{c}}
$$

and:

$$
\frac{S_{o}-S}{\theta_{h}}-\frac{\mu X}{Y}
$$

One of the kinetic models used to describe the relationship between microbial growth and the concentration of growth-limiting substrate as has been presented earlier (Equation 3) is given by (Contois, 1959) as:

$$
\mu=\frac{\mu_{m} S}{b X+S}
$$

Combining (75), (76) and (77) and simplifying yields:

$$
\frac{S}{S_{o}}=\frac{K}{\mu_{m} \theta_{h}+K-\frac{\theta_{h}}{\theta_{c}}\left(1+k_{d} \theta_{h}\right)}
$$

where, $K=Y b$ is a dimensionless parameter. Thus it is evident that substrate removal efficiency depends on the ratio $\frac{\theta_{h}}{\theta_{c}}$. In a completely mixed reactor, $\theta_{c}=\theta_{h}$ so that (78) reduces to:

$$
\frac{S}{S_{o}}=\frac{K}{\theta_{h}\left(\mu_{m}-k_{d}\right)+K-1}
$$

In the flocculent and attached film reactors $\theta_{c}>\theta_{h}$ (Young and McCarty, 1968), as the SRT becomes large at short HRT $\left(<5\right.$ days), the ratio $\frac{\theta_{h}}{\theta_{c}}$ tends to zero so that for flocculent and attached film reactors Equation 78 reduces to:

$\frac{S}{S_{o}}=\frac{K}{\mu_{m} \theta_{h}+K}$

Since the assumption $\theta_{c}>>\theta_{h}$, is valid for most flocculent and attached film reactor, Equation 80 can be used to estimate the substrate removal efficiency of flocculent and attached film reactors and in any case, Equation 80 will represent the maximum performance to be expected from any flocculent or attached film process for a given vale of $\theta_{h}, \mu_{m}$ and $K$. In the case of attached film processes, it should be noted that the model (Equation 78) removes the capability to distinguish between different media characteristics in predicting the performance of a given reactor configuration since these characteristics would be reflected in the $\theta_{c}$ term. If $\theta_{c}$ the SRT is known for a given reactor configuration, Equation 78 can be used directly to predict precisely the substrate removal efficiency. Also from the definition of efficiency (Equation 37), it can be shown by combining (37) and (80) that the efficiency $(\eta)$ can be given by:

$\eta=100\left[1-\left(\frac{K}{\mu_{m} \theta_{h}+K}\right)\right]$

The dimensionless parameter, $K$ have been used as an indicator of the level of inhibition present in the reactor system (Hill, 1982; Hashimoto and Robinson, 1984) with high values usually indicating high levels of inhibition. $K$ can be determined using a CSTR to determine values for plotting the linearized form of Equation 79, i.e.,: 


$$
\frac{S}{S_{o}}=\theta_{h}\left(\frac{\mu_{m}+K}{K}\right)+\frac{K-1}{K}
$$

The intercept equals $\frac{K-1}{K}$. The value of $K$ for swine waste can be determined from a relationship given by (Hashimoto and Robinson, 1984), i.e.,:

$$
K=0.6+0.0206 e^{0.051 S_{o}}
$$

In addition to the Bolte and Hills (1985) model presented above, the following model proposed by Metcalf and Eddy (1978) for the analysis of trickling filter can be adapted for Down-flow Stationary Fixed Film (DSFF) Reactors and anaerobic reactors operated in downward mode:

$$
\frac{S}{S_{o}}=e^{-\left[\left(f h k_{o}\right) \frac{W Z}{Q}\right]}
$$

where, $f$ is proportionality factor $(=E / S), E$ is effectiveness factor $0 \leq \mathrm{E} \leq 1, S$ is effluent substrate concentration $(\mathrm{mg} \mathrm{BOD} / \mathrm{L}), S_{o}$ is the overall influent substrate concentration including recycled fraction if provided $(\mathrm{mg} \mathrm{BOD} / \mathrm{L}), h$ is the thickness of slime layer $(\mathrm{m}), k_{o}$ is the maximum reaction rate $\left(\mathrm{d}^{-1}\right), W Z$ is the surface area of filter media $\left(\mathrm{m}^{2}\right)$ and $Q$ the volumetric flow rate $\left(\mathrm{m}^{3} / \mathrm{d}\right)$.

The equation was developed by carrying out a mass balance about an elemental volume of slime layer (attached film) of thickness $h$ attached to a media surface of area $W d Z$. The relationship developed by (Atkinson et al., 1974) to describe the rate of heat flux of organic materials into the slime layer, assuming that diffusion into the slime layer controls the rate of reaction and that there is no concentration gradient across the liquid, i.e.,:

$$
\frac{d S}{d t}=\frac{E h k_{o} \bar{S}}{K_{s}+S}
$$

Where:

$\bar{S}=$ Average BOD concentration in the bulk liquid in volume of element and

$K_{s}=$ The half velocity constant

The term $\left(f h k_{o}\right)$ can be condensed into a constant and determined as a slope of a plot of $\log \left(\frac{S}{S_{o}}\right) v s\left(\frac{W Z}{Q}\right)$.

Other similar models that have been proposed and which can be utilized in the analysis of DSFF reactors include that of (Eckenfelder, 2000; Bruce and Merkens, 1973) which are given respectively in Equation 86 and 87:

$$
\frac{S}{S_{o}}=\exp -\left[K Z S_{a}^{m}\left(\frac{A}{Q}\right)^{n}\right]
$$

$$
\frac{S}{S_{o}}=\exp -\left[K_{T} S_{a}^{c} Q_{v}^{-b}\right]
$$

where, $K, K_{T}$ are observed removal coefficient $(\mathrm{m} / \mathrm{d}), S_{a}$ is specific surface area $\left(=A_{s} / V\right)\left(\mathrm{m}^{2} / \mathrm{m}^{3}\right), A_{s}$ surface area of media $\left(\mathrm{m}^{2}\right), V$ volume of reactor $\left(\mathrm{m}^{3}\right), Q$ volumetric flow rate $\left(\mathrm{m}^{3} / \mathrm{d}\right), Q_{v}$ specific volume flow rate $\left(\mathrm{m}^{3} / \mathrm{m}^{3} / \mathrm{d}\right)$, $A$ cross-sectional area of filter $\left(\mathrm{m}^{2}\right)$ and $m, n, b, c$ are empirical constants.

\section{Dynamic Models}

In the models so far presented, steady state conditions were assumed to simplify the set of non-linear differential equations that results from cell and substrate mass balances. The steady-state models which were before the advent of analog-digital computer simulations, however, cannot be used to predict process performance during start-up and other transient operating conditions. The Monod type models that described the relationship between growth rate and substrate utilization also implies growth rate continues to increase asymptotically with increase in substrate concentration. It has long been known that as the substrate increases beyond certain level, substrate inhibition sets in. Monod type models cannot therefore predict the inhibitory effects of high levels of substrate concentration. Dynamic models, on the other hand, can be used to make such predictions.

Quite a good number of models have been proposed to account for inhibition due to various parameters. Mossey (1983) suggested the introduction of a factor, $I$ (known as pH inhibition factor) into the Monod model to account for the effects of extremes of $\mathrm{pH}$. The proposed model is shown in Equation 88:

$\frac{d S}{d t}=\frac{K I X S}{K_{s}+S}$

where, $I$ is the $\mathrm{pH}$ inhibition factor which takes the value of 1.0 at the optimum $\mathrm{pH}$ range of 6-8 and progressively reduces to 0.1 at $\mathrm{pH}$ range of 8-9.5 or falls from 6 to 4.5 to account for the fact that the rate of bacterial metabolism decreases to $1 / 10$ of its normal value at these $\mathrm{pH}$ extremes.

Mossey (1983) also suggested the modeling of bactericidal effects of extremes of acidity and alkalinity by varying the value of decay coefficient $k_{d}$ in the yield equation given in (89):

$\frac{d X}{d t}=Y \frac{d S}{d t}-k_{d} X$ 
Allowing it to rise from its normal value of 0.02 (for acetoclastic bacteria at $35^{\circ} \mathrm{C}$ ) up to 1.0 at $\mathrm{pH}$ values below 3.0 and above 11.0 to stimulate rapid death of these bacteria. However, the most widely accepted inhibition models are those developed by Andrews and Hill and Barth (Andrews, 1968; 1969; Andrews, 1971; Graef and Andrews, 1973; Hill and Barth, 1977). To predict the dynamic behaviour of anaerobic reactors under the inhibitory effects of high substrate concentration Andrews (1968) adopted Haldane (1965) enzyme inhibition function to modify Monod's equation as follows:

$$
\mu=\frac{\mu_{m}}{\left[1+\left(\frac{K_{s}}{S}\right)+\left(\frac{S}{K_{i}}\right)\right]}
$$

where, $K_{i}$ is the inhibition constant which is numerically equal to the maximum substrate concentration at $\mu=\frac{1}{2} \mu_{m}$ in the presence of inhibition and $K_{s}$ is the saturation (half velocity) constant, i.e., the minimum concentration at which $\mu=\frac{1}{2} \mu_{m}$ in the absence of inhibition. These are illustrated in Fig. 11. As can be seen from the figure, $K_{i}$ equals infinity in the absence of inhibition, thus reducing Equation 90 to that of Monod. One of the effects of inhibition as can be seen from the figure is to reduce the maximum specific growth rate. For a given value of $K_{i}$ less than infinity, the maximum attainable $\left(\mu_{m}\right)$ is obtained by setting the first derivative of Equation 90 equal to zero, thus (Equation 91):

$$
\bar{\mu}_{m}=\frac{\mu_{m}}{\left[1+2\left(\frac{K_{s}}{K_{I}}\right)^{0.5}\right]}
$$

where, $\bar{\mu}_{m}$ is the maximum specific growth rate in the presence of inhibition $\left(\mathrm{d}^{-1}\right)$. The substrate concentration at this growth rate is given by:

$\hat{S}=\left(K_{s} K_{i}\right)^{0.5}$

where, $\hat{S}$ is the substrate concentration at maximum specific growth attainable in the presence of inhibition $(\mathrm{mg} / \mathrm{L})$. To account for the effect of inhibition-causing un-ionized volatile acids and hence $\mathrm{pH}$ (since the degree of ionization is a function of $\mathrm{pH}$ ), Equation 90 was modified by Andrews (1969) as follows:

$$
\mu=\frac{\mu_{m}}{\left[1+\left(\frac{K_{s} K_{a}}{[S]\left[H^{+}\right]}\right)+\left(\frac{[S]\left[H^{+}\right]}{K_{i} K_{a}}\right)\right]}
$$

where, $\left[H^{+}\right]$is hydrogen ion concentration and $[S]$ is the total substrate concentration $\approx$ ionized acid concentration at $\mathrm{pH} \geq 6.0$ and $K_{a}$ is the ionization constant $\left(10^{4-5}\right.$ for acetic acid). The toxic loading effect was accommodated in the model by assuming that the rate of organism kill is first order with respect to the concentration of toxic agents as defined in Equation 94 (Andrews and Graef, 1971):

$$
\frac{d X_{T}}{d t}=k_{T} X_{T}
$$

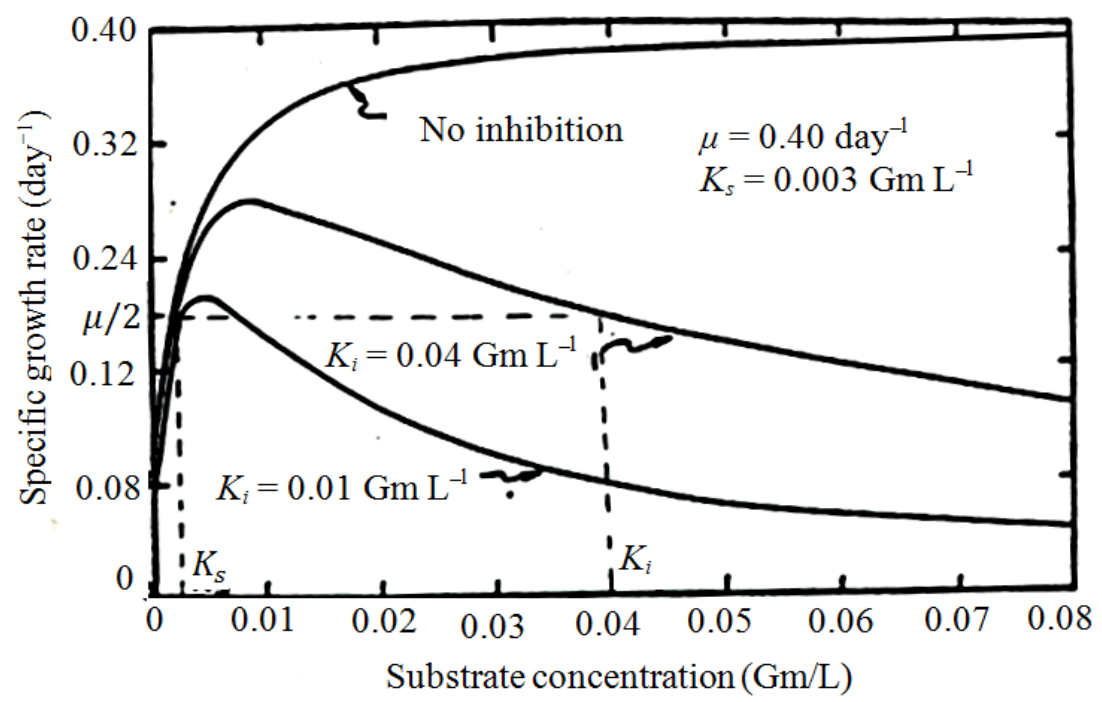

Fig. 11. Substrate inhibition function (Andrews, 1969) 
where, $\frac{d X_{T}}{d t}$ is the rate of organism kill, $k_{T}$ toxicity rate coefficient (mg/L.s) and $S_{T}$ the concentration of toxic materials $(\mathrm{mg} / \mathrm{L})$. To account for mass transfer and accumulation in the liquid and gaseous phase for such materials as carbon dioxide, bi-carbonate and cations Andrews (1971) has since expanded the original model.

The dynamic model was further modified by (Hill and Barth, 1977) to account for inhibition due to high levels of free ammonia by adding a term to growth rate equation used by Andrews (1969), i.e.,:

$$
\mu=\frac{\mu_{m}}{\left[1+\left(\frac{K_{s} K_{a}}{[S]\left[H^{+}\right]}\right)+\left(\frac{[S]\left[H^{+}\right]}{K_{i} K_{a}}\right)+\left(\frac{\left[N H_{3}\right]}{K_{N H_{3}}}\right)\right]}
$$

where, $\left[\mathrm{NH}_{3}\right]$ is the concentration of un-ionzed ammonia $(\mathrm{mg} / \mathrm{L})$ and $K_{N H 3}$ inhibition coefficient for free ammonia. The modified dynamic model was used to predict the dynamic responses during the digestion of poultry and swine manure to within $10 \%$ of the actual field data for the parameter of volatile acids (Hill and Barth, 1977).

The developed growth rate models are combined with the biomass and substrate mass balance equations and solved. Although the standard method of solution has been the use of computer simulations (Andrews, 1969; Fox and Rice, 1969) have shown that analytical solutions are possible and fairly easy. Obviously improvement will continue to be made on the existing dynamic models as well as the development of new ones. The development of a comprehensive model of the anaerobic digestion process of farm animal wastes will obviously be a breakthrough.

\section{Kinetics of Biogas Production}

\section{Stoichiometric Model}

The amount of biogas (methane and carbon dioxide) that can be produced from a waste of known chemical composition can be estimated from the stoichiometry of the overall anaerobic reaction involved. Bushwell and Muchler (1952) presented a simplified general formula for anaerobic conversion of typical substrate of the form $\mathrm{C}_{n} \mathrm{H}_{a} \mathrm{O}_{b}$ to methane and carbon dioxide, i.e.,:

$$
\begin{aligned}
& \mathrm{C}_{n} \mathrm{H}_{a} \mathrm{O}_{b}+\left(n-\frac{a}{4}-\frac{b}{2}\right) \mathrm{H}_{2} \mathrm{O} \rightarrow\left(\frac{n}{2}-\frac{a}{8}-\frac{b}{4}\right) \mathrm{CO}_{2} \\
& +\left(\frac{n}{2}-\frac{a}{8}-\frac{b}{4}\right) \mathrm{CH}_{4}
\end{aligned}
$$

For waste of the form $C_{n} H_{a} O_{b} N_{c}$ such as protein, Peavy et al. (1985) gave the formula:

$$
\begin{aligned}
& \mathrm{C}_{n} \mathrm{H}_{a} \mathrm{O}_{b} \mathrm{~N}_{c} \\
& +\left(n-\frac{a}{4}-\frac{b}{2}+\frac{3 c}{4}\right) \mathrm{H}_{2} \mathrm{O} \rightarrow\left(\frac{n}{2}+\frac{a}{8}-\frac{b}{4}-\frac{3 c}{8}\right) \mathrm{CH}_{4} \\
& +\left(\frac{n}{2}-\frac{a}{8}+\frac{b}{4}+\frac{3 c}{8}\right) \mathrm{CO}_{2}+\mathrm{cNH}_{3}
\end{aligned}
$$

The above stoichiometric relationships do into take into account that fact that a portion of the substrate is converted into cells. It is therefore the theoretical maximum yield.

\section{Empirical Models}

The rate of methane production can also be estimated by calculating the methane equivalent of the net COD reduction, i.e., total $\mathrm{COD}$ minus $\mathrm{COD}$ converted to biomass. The relevant equation is given by (Kugleman and Jerris, 1981; Benefield and Randall, 1980) as follows:

$$
\gamma=\gamma_{o}[\Delta S-1.42 \Delta X]
$$

where, $\gamma$ is methane production rate $(\mathrm{L} / \mathrm{d}), \gamma_{0}$ litters of methane produced per gram COD at STP $(=0.35 \mathrm{~L} / \mathrm{g}$ COD at STP), $\Delta S$ the ultimate COD removal rate $(\mathrm{g} / \mathrm{d})$ $\left[=\mathrm{Q}\left(\mathrm{S}_{0}-\mathrm{S}_{1}\right)\right], \mathrm{Q}$ the influent flow rate $(\mathrm{L} / \mathrm{d}),\left(S_{0}-S_{l}\right)$ the COD reduction $(\mathrm{g} / \mathrm{L}), \Delta X$ the daily biomass production (g cell/ultimate $\mathrm{BOD} / \mathrm{d}$ ) and 1.42 the ultimate BOD per gram cell.

In terms of volume per unit volume of reactor, methane production rate can be estimated using the relationship developed by Chen and Hashimoto (1978), i.e.,:

$$
\gamma_{v}=\frac{\beta_{o} S_{o}}{\theta_{h}}\left[1-\left(\frac{K}{\mu_{m} \theta_{h}-1+K}\right)\right]
$$

where, $\gamma_{v}$ is the volumetric methane yield $\left(\mathrm{LCH}_{4} / \mathrm{L}\right.$ of reactor $\mathrm{vol} / \mathrm{d}), \beta_{\mathrm{o}}$ ultimate methane yield (L/g VS added as HRT tends to infinity), $S_{o}$ the influent total volatile solids concentration, $\theta_{h}$ the hydraulic retention time (d), $K$ the kinetic parameter (dimensionless) and $\mu_{m}$ the maximum specific growth rate $\left(\mathrm{d}^{-1}\right)$.

For a given loading rate $\frac{S_{o}}{\theta_{h}}$, the volumetric methane production rate depends on the ultimate methane yield $\beta_{o}$ which is a function of the type and biodegradability of the material. It also depends on the kinetic parameters $\mu_{m}$ the maximum specific growth rate and the kinetic parameter, $K$. The maximum growth rate, as has already been pointed out, is a function of temperature. $K$ is a function of both the influent VS concentration and waste type. The maximum methane production is obtained by taking the derivative of $\gamma_{v}$ with respect to $\theta_{h}$ and equating to zero, i.e.,:

$$
\gamma_{v_{\max }}=\frac{\beta_{o} S_{o} \mu_{m}}{\left(1+K^{-\frac{1}{2}}\right)^{2}}
$$




\begin{tabular}{lllc}
\multicolumn{4}{l}{ Table 2. Ultimate methane yield for livestock waste } \\
\hline Specie & Ration & Temp $\left({ }^{\circ} \mathrm{C}\right)$ & $(\mathrm{L} \mathrm{CH} / \mathrm{g} \mathrm{VS})$ \\
\hline Beef & $18 \%$ silage & 55.0 & $0.35-0.38$ \\
& 20\% roughage & 60.0 & 0.280000 \\
Dairy & $58-68 \%$ silage & 32.5 & 0.240000 \\
& $72 \%$ Roughage & 60.0 & 0.170000 \\
\hline
\end{tabular}

${ }^{\mathrm{a}}$ Hashimoto et al. (1981)

Which occurs at $\theta_{h}=\frac{1+K^{-\frac{1}{2}}}{\mu_{m}}$. The ultimate methane yield, $\beta_{o}$ is determined by plotting the steady-state methane yield (L/g VS added) $v s \frac{1}{\theta_{h}}$ and determining by extrapolation the methane yield corresponding to $\frac{1}{\theta_{h}}=0$. It can also be determined by incubating a known amount of substrate until a negligible amount of methane is produced (Hashimoto et al., 1981). Typical values of ultimate methane yield for beef and dairy waste is given in Table 2.

Finally when it is desired to estimate biogas yield per mass of volatile solids added, the model developed by (Singh, 1977; Singh and Shulte, 1984) can be used, i.e.,:

$$
\gamma=\gamma_{m}\left[1-e^{-k\left(t-\theta_{c}^{m}\right)}\right]
$$

where, $\gamma$ is gas production at STP per unit VS added $\left(\mathrm{m}^{3} / \mathrm{kg} \mathrm{VS}\right), \gamma_{m}$ the total gas produced at infinite time, i.e., the maximum produceable amount of biogas during digestion $\left(\mathrm{m}^{3} / \mathrm{kg}\right.$ VS added), $k$ the reaction rate constant $\left(\mathrm{d}^{-1}\right), \theta_{c}^{m}$ the washout time (minimum SRT) at the given temperature, $t$ the time required for complete conversion of substrate into biogas and end products at a given temperature. Where $\gamma_{m}, k$ and $\theta_{c}^{m}$ are known at one temperature $T_{1}$, methane yield, $\gamma_{T 2}$ at another temperature $T_{2}$ can be estimated by applying temperature correction factor as follows (Schulte et al., 1979):

$$
\gamma_{T_{2}}=\gamma_{m} \theta_{h_{1}}\left(T_{2}-T_{1}\right)\left[1-e^{-\left\{k\left(t-\theta_{c}^{m}\right) \theta_{h_{2}}^{\left(T_{2}-T_{1}\right)}\right\}}\right]
$$

\section{Conclusion}

Presented in this review are the various basic kinetic models that have been developed for describing the generation of biomass and utilization of substrates in anaerobic fermentation processes. The stoichiometric and empirical models for the prediction of biogas production are also presented. The models are very simple and implementable and can be useful in the optimization and design of anaerobic reactors.

\section{References}

Agardy, F.J., R.D. Cole and E.A. Pearson, 1963. Kinetic and activity parameters of anaerobic fermentation systems. PhD Thesis, University of California.

Andrews, J.F., 1968. A mathematical model for the continuous culture of microorganisms utilizing inhibitory substrates. Biotechnol. Bioengin., 10: 707-723. DOI: 10.1002/bit.260100602

Andrews, J.F., 1971. Kinetic Models of Biological Waste Treatment Processes. In: Biotechnology and Bioengineering Symposium no. 2, Canale, R.P. (Ed.), John Wiley and Sons, New York, pp: 5-33.

Andrews, J.F., R.D. Cole and E.A. Pearson, 1964. Kinetics and characteristics of multi-stage methane fermentation. University of California, Berkeley. California.

Andrews, J.F. and S.P. Graef, 1971. Dynamic Modeling and Simulation of Anaerobic Digestion Process. In: Anaerobic Biological Treatment Processes. Gould, R.F. (Ed.), American Chemical Society, Wash, pp: 126-162.

Andrews, J.F., 1969. Dynamic model of anaerobic digestion process. Adv. Chem., 105: 126-162. DOI: 10.1021/ba-1971-0105.ch008

Atkinson, B.I., J. Davis and S.Y. How, 1974. The overall rate of substrate uptake by microbial films. Part I and II. Trans. Inst. Chem. Eng. IChE.

Benefield, L.D. and C.W. Randall, 1980. Biological Process Design for Wastewater Treatment. 1st Edn., Prentice-Hall, Englewood Cliffs, ISBN-10: 013076406X, pp: 526.

Bolte, J.P. and D.T. Hill, 1985. Modeling suspended particle-attached growth anaerobic reactors. Proceedings of the 5th International Symposium on Agricultural Wastes, Dec.16-17, Chicago, Illinois, USA, pp: 104-115.

Bruce, A.M. and J.C. Merkens, 1973. Further studies of partial treatment of sewage by high-rate biological filtration. J. Inst. Water Pollut. Contr., 72: 499-523.

Bushwell, A.M. and M.F. Mueller, 1952. Mechanism of methane fermentation. Indust. Eng. Chem., 44: 550-552. DOI: 10.1021/ie50507a033

Chen, Y.R. and A.G. Hashimoto, 1978. Kinetics of methane fermentation. Biotechnol. Bioeng. Symp., 8: 269-282.

Contois, D.E., 1959. Kinetics of bacterial growth: Relationship between population density and specific growth rate of continuous cultures. Microbiology, 21: 40-50.

DOI: $10.1099 / 00221287-21-1-40$

Echiegu, E.A. and A.E. Ghaly, 1993. Kinetics of a continuous-flow no-mix anaerobic reactor. Energy Sources, 15: 433-449.

DOI: $10.1080 / 00908319308909037$ 
Echiegu, E.A. and A.E. Ghaly, 2014. Kinetic modelling of continuous-mix anaerobic reactors operating under diurnally cyclic temperature environment. Am. J. Biochem. Biotechnol., 10: 130-142. DOI: 10.3844/ajbbsp.2014.130.142

Echiegu, E.A., 1992. Performances of a continuous mix anaerobic reactor operating on dairy manure under two diurnal temperature ranges. $\mathrm{PhD}$ Thesis, Technical University of Nova Scotia, Halifax Nova Scotia, Canada.

Eckenfelder, W.W., 2000. Industrial Water Pollution Control. 3rd Edn., McGraw-Hill, Boston, ISBN-10: 0071162755, pp: 584.

Fox, G.E. and P.A. Rice, 1969. Discussion of Andrews. J. San. Eng. Div.

Ghaly, A.E. and E.A. Echiegu, 1993. Kinetics of a continuous-flow no-mix anaerobic reactor. Energy Sources, 15: 433-449. DOI: $10.1080 / 00908319308909037$

Grady, C.P.L. and C.L. Lim, 1980. Biological Wastewater Treatment: Theory and Applications. 1st Edn., M. Dekker, New York, ISBN-10: 0824710002, pp: 963.

Graef, S.P. and J.F. Andrew, 1973. Mathematical modelling and control of anaerobic digestion of wastewater.

Haldane, J.B.S., 1965. Enzymes. 1st Edn., Massachusetts Institute of Technology Press, Cambridge, ISBN-10: 0262080214, pp: 235.

Hashimoto, A.G. and S.A. Robinson, 1984. Two-phase system to convert straw and manure to methane. Am. Society Agric. Eng.

Hashimoto, A.G., Y.R. Chen, V.H. Varel and R.L. Prior, 1981. Anaerobic Fermentation of Beef Cattle Manure: Final Report. 1st Edn., Solar Energy Research Institute, Washington, D.C., pp: 66.

Hill, D.T., 1982. A comprehensive dynamic model for animal waste methanogenesis. Trans. ASABE, 25: 1374-1380. DOI: $10.13031 / 2013.33730$

Hill, D.T. and C.L. Barth, 1977. A dynamic model for simulation of animal waste digestion. J. Water Pollut. Control Federat., 49: 2129-2143.

Holm-Hansen, O. and C.R. Booth, 1966. The measurement of adenosine triphosphate in the ocean and its ecological significance. Luminol. Oceanogra., 11: 510-519. DOI: $10.4319 /$ lo. 1966.11.4.0510

Kugleman, I.J. and J.S. Jerris, 1981. Anaerobic Digestion. In: Sludge Treatment, Eckenfelder, W.W. and Santhanan, C.J. (Eds.), Mercel Dekker NY.

Lawrence, A.M. and P.L. McCarty, 1969. Kinetics of methane fermentation in anaerobic treatment. J. WPCF, 41: R1-R17.

Lawrence, A.M. and P.L. McCarty, 1970. Unified basis for biological treatment design and operation. J. San. Eng. Div., 96: 757-777.
Lawrence, A.W., 1971. Application of process kinetics to design of anaerobic processes. Adv. Chem., 105: 163-190. DOI: 10.1021/ba-1971-0105.ch009

Mccarty, P.L., 1964. Anaerobic waste treatment I: Chemistry and microbiology, II: Environmental requirement and control. III: Toxic material and their control. IV: Process design. Public Works, 95: 107-177.

Metcalf, L. and H.P. Eddy, 1978. Wastewater Engineering Treatment Disposal Reuse. 2nd Edn., McGraw-Hill, ISBN-10: 007041677X, pp: 920.

Metcalf, L. and H.P. Eddy, 2003. Wastewater Engineering: Treatment and Reuse. McGraw-Hill Education, Boston, ISBN-10: 0070418780, pp: 1819.

Monod, J., 1950. The growth of bacterial culture. Annual Rev. Microbiol., 3: 371-394.

Mossey, F.E., 1983. Mathematical modelling of the anaerobic digestion process: Regulatory mechanisms for the formation of short-chain volatile acids from glucose. Water Sci. Technol., 15: 209-232.

O'Rourke, J.T., 1968. Kinetics of anaerobic treatment at reduced temperature. $\mathrm{PhD}$ Thesis, Stanford University.

Parkin, G. and W. Owen, 1986. Fundamentals of anaerobic digestion of wastewater sludges. J. Environ. Eng., 112: 867-920.

DOI: 10.1061/(ASCE)0733-9372(1986)112:5(867)

Peavy, H.S., D.R. Rowe and G. Tchobanoglous, 1985. Environmental Engineering. 7th Edn., McGraw-Hill, New York, ISBN-10: 0071002316, pp: 719.

Preterious, W.A., 1969. Anarobic digestion III: Kinetics of anaerobic fermentation. Water Res., 3: 545-558.

Schulte, D.D., V. Fields and D. Kraft, 1979. An economic assessment of anaerobic digestion system using separable programming. American Society of Agricultural Engineers.

Singh, R.K., 1977. Computer simulation of energy recovery through anaerobic digestion of livestock manure. MSc Thesis, University of Manitoba.

Singh, R.K. and D.D. Schulte, 1984. Mathematical modeling of net energy production through anaerobic digestion of livestock waste. American Society of Agricultural Engineers.

Stewart, M.J., 1958. Reaction kinetics and operational parameters of continuous-flow anaerobic-fermentation processes. 1st Edn., Sanitary Engineering Research Laboratory, University of California, pp: 142.

Thimann, K.V., 1955. The life of bacteria. Soil Sci., 80: 1-87.

Toerien, D.F., M.L. Siebert and W.H.J. Hattingh, 1977. The bacterial nature of the acid-forming phase of anaerobic digestion. Water Res., 1: 497-507. DOI: 10.1016/0043-1354(67)90026-7

Wehner, J.F. and R.F. Wilhelm, 1956. Boundary conditions of flow reactor. Chem. Eng. Sci., 6: 89-93. DOI: 10.1016/0009-2509(56)80014-6

Young, J.C. and P.L. McCarty, 1968. The anaerobic filter for waste treatment. Stanford University. 